\section{GREENING OF INDUSTRY NETWORK NOTICEBOARD}

\author{
REGIONAL ENVIRONMENTAL MANAGEMENT - \\ IS IT SUSTAINABLE?
}

\section{Editorial by Grace Wever**}

Over the past decade, a strong trend toward regional environmental management has emerged in the United States with the recognition that population and economic centres have grown up around abundant water and other natural resources. Policy-makers and regulators gain certain economies of scale through this approach. A powerful analytical perspective can also be obtained by tracing policy development, and predicting the effectiveness of future implementation vehicles in addressing risks and costs, and maximising benefits.

Given the importance of regional economies to the level of national economic strength, it is important to assess the effects of environmental management strategies on competitiveness. The Great Lakes region, the manufacturing heartland of North America, can serve as a model for this analysis. This region has a wealth of natural resources, including a system of five large lakes with $20 \%$ of world's surface freshwater. Its economy represents about $60 \%$ of US auto production, $70 \%$ of steel, and a vast supplier network. Over the past two decades, the region has stripped out about $20 \%$ of its manufacturing jobs through vigorous restructuring. A slow economic recovery is underway, encouraged by productivity gains, new partnerships, and an infusion of capital into R \& D, technologies and equipment.

The region has been called an 'experimental model' for environmental management, and in the US, there has been a strong movement by regulators toward extending Great Lakes-specific strategies to other regions. However, it is important to recognise that while some 'experiments' have succeeded, many others have sparked controversy.

\section{What Approaches Have Worked}

Successful strategies over the past three decades included stricter discharge standards, construction of wastewater treatment facilities, and a long list of voluntary pollution prevention and responsible stewardship programmes initiated by business. These programmes, driven in part by the landmark 1972 Canada US Great Lakes Water Quality Agreement, produced many benefits, including a significant decrease of chemical emissions, decreased chemical levels in water, sediment, and tissues, and recoveries in wildlife and aquatic populations.

\section{What Approaches Remain Controversial}

The concept of an ecosystem-based approach to management (proposed in a revision to the 1972 Agreement) has yet to be successfully applied in the Great Lakes region. This concept requires that all media and sources of pollutants are considered. It also requires that environmental, natural resource, social and economic factors are evaluated and integrated into decision-making. Yet nowhere have the

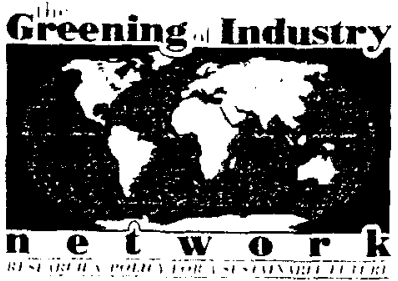

effects of regional policy and management strategies on the economy or on social systems been evaluated.

It is equally clear that entire regions should not be considered single ecosystems. Applying policy or management strategies across the board is inappropriate, if the objective is to provide equal protection to human health and environment. Lakes Superior and Ontario, for example, have very different physical and chemical profiles, hence different biota, yet the US EPA's recently published Great Lakes Water Quality Guidance proposes a single set of Basin-wide discharge standards.

With respect to regional priorities, regulators and advocacy groups have focused almost exclusively on chemicals and their effects, to the exclusion of other equally compelling problems (e.g. land-use, biodiversity, exotic species, and brownfield redevelopment). Policy has also evolved over this period from pollution control towards more stringent policies such as zero discharge and virtual elimination, toward zero use, and finally to chemical bans of large classes of chemicals.

Over this period, regulatory approaches have become more costly, address smaller and smaller risks, and also produce smaller benefits. A major flaw in this approach is the attempt to optimise around a single variable (chemicals in this case), rather than taking a systems-based, or life-cycle approach which examines impacts at each stage and includes impacts from all sectors involved. Regulatory agencies have also continued to regulate using a singlemedia, rather than a multi-media approach. This discourages sound environmental approaches by businesses, considering waste streams across all media, including a broad life-cycle analysis approach.

Pressures continue from advocacy groups and from the International Joint Commission to ban whole classes of chemicals such as organochlorines, and even the manufacture and use of chlorine. EPA has recently introduced a recommendation for the new Clean Water Act to develop a strategy directed at banning these substances, a complete turnaround from its position a few months earlier. Yet, it is clear that different chlorine-containing compounds have distinctly different properties and effects, and human health data supporting such drastic measures is lacking. Studies are now underway that should resolve ambiguous results from earlier, flawed research. Given the potential economic impacts of such management approaches (e.g. chlorine chemistry is involved in $40 \%$ of US GDP), it is time to defuse this policy debate, decouple it from public pressures, and regroup until the scientific data is in.

\section{The Future}

The Great Lakes region is not a single ecosystem. Management approaches should be watershed- and multimedia-based, and take into account the extent to which individual ecosystem units are interlinked. The watershed approach is a sound one, and has been successfully used as the basis for RAPs (Remedial Action Plans) and LAMPs (Lakewide Management Plans) in the Great Lakes region. 
LAMPs, which integrate a number of existing programmes on both point and nonpoint sources of pollution, also offer the public the opportunity to participate in and influence local strategies.

Decisions with respect to chemicals need to be based on a life-cycle approach that incorporates sound scientific and technical information, as well as reliable cost/risk/benefit data for alternative approaches. Identifying and filling critical information gaps is essential before effective policies and management strategies can be devised. Policies based on Draconian measures, driven by public pressure, rarely lead to responsible use of scarce resources.

Improvements in the management of chemicals have brought the region to the point where their impacts on environment and health have been significantly reduced, thus priorities need to be shifted. Emerged issues of increasing importance include habitat loss, biodiversity, landuse, and brownfield. Regional indicators need to be developed which support the concept of sustainability, including environmental, economic, natural resource, and societal concerns.

\section{Principles for More Effective Regional Management}

- Broaden the leadership circle involved in regional environmental research, as well as management, and create more effective communications vehicles.

- Ensure that more objective processes are used to educate stakeholders and to gather input.

- Define responsibilities and create greater accountability for institutions/governance bodies responsible for regional policy and implementation vehicles. Eliminate overlap and duplication between such bodies, and minimise the creation of new ones.

- Adopt a 'ready, aim, fire' management philosophy (rather than the more common variations on this sequence):

- Get 'ready' by assuring that a sound scientific and technical base is in place, and that resources are in place to provide this foundation.

- 'Take aim' by ensuring that the right priorities have been set, based on good science as well as risk, benefit and cost data.

- Adopt a comprehensive, region-wide binational strategy before 'firing off' strategies and implementation plans that are uncoordinated or duplicative. The Great Lakes region, despite its long management history, does not yet have. such a comprehensive binational strategy, yet its plans and programmes are growing and increasingly costly.

- Avoid Draconian policies and solutions, and instead create policies that are consistent with sustainable development by integrating environmental, natural resource management, economic, and societal factors.

- Adopt an ecosystem-based approach to management, remembering that regions are not single ecosystems. The watershed approach embodied in vehicles such as Remedial Action Plans and Lakewide Management Plans is more consistent with an ecosystem- based approach, than are Basin-wide standards setting approaches such as the Great Lakes Water Quality Guidance.

- Build in a process of continuous improvement so that as new and better information becomes available, priorities can be shifted and resources redirected.

- Foster cooperation at the highest policy and planning levels. EPA and Environment Canada's cooperative approach to evaluating the State of the Great Lakes Ecosystem will be an important vehicle to educate stakeholders and strengthen decision-making.

** Dr. Crace Wever is Vice President of Environmental Affairs for the Council of Creat Lakes Industries (CCLI), a public policy body. She also serves as Director and corporate liaison to the Council of Creat Lakes Industries for Eastman Kodak Company in Rochester, New York, where she has been employed since 1981.

\section{NETWORK UPDATE}

Third International Research Conference

From Greening to Sustaining: Transformational Challenges for the Firm

Copenhagen, November 13-15, 1994.

Fourth International Research Conference

Research and Practice: Leaning to Build Sustainable Industries for Sustainable Societies

Toronto, November 12-14, 1995.

Conference Coordinator: Professor Nigel Roome, York University, Canada, plans to release the 1995 Call for Papers at our 1994 conference.

A Network Vision Statement is now available and has been mailed to all participants, explaining overall vision and mission as well as specific activity plans.

\section{Electronic Network:}

We have begun pilot testing of an electronic communications network with TogetherNet, a computer information and communications network system which focuses on issues related to the environment, sustainable development and the United Nations. According to their prospectus:

It is a user-friendly, interactive network that puts you in touch with the people, projects and organisations working in service to the Earth and its inhabitants. It is a project of the Together Foundation for Global Unity, a 501 (c) (3) non-profit, non-governmental organisation. The primary TogetherNet system is accessed through a graphic-user interface similar to the Macintosh or Microsoft Windows 3.1 desktop. With the graphical software, the TogetherNet user navigates the system through the simple and familiar point-and-click method. TogetherNet also is accessible through a 'command line interface' of any standard computer modem communications software, or via telnet.

TogetherNet has an on-line library of articles and background papers on environmental and human rights topics as well as other related issues. Information from 
the United Nations, including the General Assembly, ECOSOC and the Security Council is available as soon as it is generated at the UN, where TogetherNet is a primary source of information for UN staff, agencies and missions. TogetherNet maintains an extensive calendar, listing environmental and human rights conferences and events worldwide with short descriptions and contact information. News sources of significant international environmental, development and human rights stories are on line, as are relevant special alerts and press releases. At no additional cost, TogetherNet subscribers may communicate with millions of users throughout the world via TogetherNet's electronic-mail gateway to the Internet. TogetherNet has more than 300 'Usenet' news groups that are relevant to global sustainability. Tens of thousands of users across the Internet participate in these conferences.

TogetherNet maintains regional hosts in New York, Caracas and Geneva. In 1994 hosts are planned for Rio de Janeiro and other cities.

We hope to demonstrate the pilot at our November 13-15 conference in Copenhagen, and to be operating in early 1995.

For further information on the Greening of Industry Network please contact:

Kurt Fischer

Greening of Industry Network

Center for Environmental Management

Tufts University, 177 College Avenue

Medford, Massachusetts 02155 U.S.A.

tel 6176285000 ext 5131 fax 6176273099

email kfischer@infonet.tufts.edu

or

Johan Schot

Greening of Industry Network

Centre for Studies of Science Technology and Society

TWr.RC 302, P.O. Box 217, University of Twente

$7500 \mathrm{AE}$ Enschede, The Netherlands

tel 3153893344 fax 3153350625

email J.W.Schot@wmw.utwente.n! 